\title{
Localization of glycine receptors in the human forebrain, brainstem, and cervical spinal cord: an immunohistochemical review
}

\author{
Kristin Baer ${ }^{* \dagger}$, Henry J. Waldvogel ${ }^{2 \dagger}$, Richard L. M. Faull' ${ }^{2}$ and Mark I. Rees ${ }^{1,3}$ \\ 1 Molecular Neuroscience, Institute of Life Science, School of Medicine, Swansea University, Swansea, UK \\ 2 Department of Anatomy with Radiology, Faculty of Medical and Health Science, University of Auckland, Auckland, New Zealand \\ 3 Institute of Medical Genetics, School of Medicine, Cardiff University, UK
}

Edited by:

Robert J. Harvey,

The School of Pharmacy, UK

Reviewed by:

Claudia Racca, Newcastle University,

UK

Jean-Michel Rigo, Universiteit Hasselt, Belgium

\section{${ }^{*}$ Correspondence:}

Kristin Baer, Molecular Neuroscience, Institute of Life Science, School of Medicine, Swansea University,

Swansea, UK.

e-mail:k.baer@swansea.ac.uk

${ }^{+}$Kristin Baer and Henry J. Waldvogel have contributed equally to this work.
Inhibitory neurotransmitter receptors for glycine (GlyR) are heteropentameric chloride ion channels that are comprised of four functional subunits, alpha1-3 and beta and that facilitate fast-response, inhibitory neurotransmission in the mammalian brain and spinal cord. We have investigated the distribution of GlyRs in the human forebrain, brainstem, and cervical spinal cord using immunohistochemistry at light and confocal laser scanning microscopy levels. This review will summarize the present knowledge on the GlyR distribution in the human brain using our established immunohistochemical techniques. The results of our immunohistochemical labeling studies demonstrated GlyR immunoreactivity (IR) throughout the human basal ganglia, substantia nigra, various pontine regions, rostral medulla oblongata and the cervical spinal cord present an intense and abundant punctate IR along the membranes of the neuronal soma and dendrites. This work is part of a systematic study of inhibitory neurotransmitter receptor distribution in the human CNS, and provides a basis for additional detailed physiological and pharmacological studies on the inter-relationship of GlyR, GABA $R$ and gephyrin in the human brain. This basic mapping exercise, we believe, will provide important baselines for the testing of future pharmacotherapies and drug regimes that modulate neuroinhibitory systems. These findings provide new information for understanding the complexity of glycinergic functions in the human brain, which will translate into the contribution of inhibitory mechanisms in paroxysmal disorders and neurodegenerative diseases such as Epilepsy, Huntington's and Parkinson's Disease and Motor Neuron Disease.

Keywords: human brain, glycine receptor, immunohistochemistry

\section{INTRODUCTION}

Glycine receptors (GlyR) belong to the superfamily of ionotropic receptors that include $\mathrm{GABA}_{\AA}$, acetylcholine receptors and glutamate (Rajendra et al., 1997; Cascio, 2002; Colquhoun and Sivilotti, 2004). They are also part of the superfamily of ligand-gated ion channels, the Cys-loop receptors (Connolly and Wafford, 2004). Recently accumulated knowledge demonstrates that the receptor structure of the Cys-loop family has an important impact on the function of the receptor (Connolly and Wafford, 2004). GlyRs are important inhibitory receptors in the central nervous system, and are especially prominent in the brainstem and spinal cord (Altschuler et al., 1986; Alvarez et al., 1997). GlyRs are strychnine sensitive and are involved in regulating inhibitory chloride influx through chloride channels to stabilize the resting potential of neurons. GlyRs form pentamers assembled from a range of subunits (currently $\alpha 1-4$, and $\beta$ subunits), (Langosch et al., 1990; Grudzinska et al., 2005). In the human, only four known functional GlyR subunits have been identified, $\alpha 1-\alpha 3$ and $\beta$ (Lynch, 2004) which are most likely to exist in heteromeric $\alpha \beta$ combinations. Defects in mammalian glycinergic neurotransmission can result in a complex motor disorder characterized by an exaggerated startle reflex and neonatal hypertonia, known as hyperekplexia (Andrew and Owen, 1997; Bakker et al.,
2006). In humans, missense and nonsense mutations in the GlyR $\alpha 1$ gene (GLRA1) and the GlyT2 transporter gene (SLC5A6) are the major cause of this disorder (Shiang et al., 1993; Rees et al., 1994, 2001, 2006; Gomeza et al., 2003), although mutations in the GlyR $\beta$ subunit (Rees et al., 2002), and the GlyR clustering protein gephyrin (GPHN; Rees et al., 2003) have also been reported. GlyRs containing the $\alpha 3$ subunit have increasing therapeutic importance, as they are involved in downstream signaling of inflammatory pain in the spinal cord (Harvey et al., 2004) and may offer novel avenues for the treatment of inflammatory pain. Despite these studies, the location of GlyR subunit combinations in human adult brain and spinal cord remain largely uncharacterized (Probst et al., 1986; Naas et al., 1991), and the biological and genetic basis of many cases of hyperekplexia and paroxysmal movement disorders remain unresolved (Harvey et al., 2008).

Early studies showed the presence of GlyR in rat and human cerebral cortex, although levels of IR were lower than those seen in spinal cord (Naas et al., 1991). GlyR-IR was prominent in apical dendrites of pyramidal neurons in layers III and IV (Naas et al., 1991). GlyRs are also present in other higher cognitive areas such as the hippocampus, where they contribute to both short- and long-term plasticity (Keck and White, 2009), in the developing 
neocortex (Flint et al., 1998), and in the mammalian amygdala of the limbic system (Danober and Pape, 1998; McCool and Botting, 2000; Dudeck et al., 2003). In addition, GlyR signaling was detected in non-neuronal cells (den Eynden et al., 2009).

In our ongoing investigations, we have utilized immunohistochemical staining methods (Waldvogel et al., 2006) to analyse the expression and synaptic localization of GlyRs in the human brainstem and spinal cord. The antibodies utilized in these studies produce a punctate immunolabelling pattern in the rat, cat or human brain (Triller et al., 1985, 1987; Kirsch and Betz, 1993; Todd et al., 1996; Alvarez et al., 1997; Colin et al., 1998; Geiman et al., 2000, 2002). In addition to GlyRs, we have described the distribution of gephyrin in the human brain (Waldvogel et al., 2003, 2009), a multifunctional protein responsible for the clustering of GlyRs at inhibitory synapses (Fritschy et al., 2008).

Recently we reported on the distribution of GlyRs in the human brain basal ganglia (Waldvogel et al., 2007). The human brain basal ganglia are a group of large subcortical nuclei involved in the complexity of motor and mood control. They include the striatum (caudate nucleus and putamen), the external (GPe) and internal (GPi) segments of the globus pallidus (GP), the substantia nigra (SN), which has two subdivisions, the substantia nigra pars compacta $(\mathrm{SNc})$ and the substantia nigra pars reticulata $(\mathrm{SNr})$, and also include the subthalamic nucleus (Graybiel, 1995). The caudate and putamen project to the output nuclei of the basal ganglia, the GPe, GPi and the SNr. The substantia nigra pars compacta contains dopaminergic, pigmented neurons which project to various regions of the forebrain especially the striatum. The neurons of the substantia nigra pars reticulata are mainly GABAergic and project to the thalamus, superior colliculus and brainstem regions (Smith et al., 1998). The predominant inhibitory receptors in the human basal ganglia are ionotropic $\mathrm{GABA}_{\mathrm{A}}$ and metabotropic GABA $_{B}$ receptors (Waldvogel et al., 1999, 2004), but there is convincing evidence from observations in animals (Sergeeva, 1998; Darstein et al., 2000; Sergeeva and Haas, 2001) and in the human brain (Naas et al., 1991) that inhibitory GlyRs also exist in the mammalian basal ganglia. Also, there is evidence that glycinergic mechanisms modulate dopaminergic, cholinergic and GABAergic functions in the striatum and the substantia nigra (Cheramy et al., 1978; Kerwin and Pycock, 1979; de Montis et al., 1982; Sergeeva, 1998; Darstein et al., 2000) and these mechanisms can be influenced by the action of ethanol (Darstein et al., 1997).

This work is a review article and summarizes these studies of the post-mortem human brain utilizing antibodies directed against GlyR subunits and immunohistochemical procedures to visualize the regional and cellular distribution of GlyRs in the forebrain and the various major nuclei of the basal ganglia, the striatum, globus pallidus, substantia nigra and the cervical spinal cord at the light and confocal laser scanning microscope levels. These investigations are specifically directed to investigate the distribution of GlyRs in these human brain regions in order to elucidate the role GlyRs may play in inhibitory mechanisms modulating human brain function.

\section{IMMUNOHISTOCHEMICAL PROCEDURES BRAIN TISSUE}

For this study, the human brain tissue was obtained from the Neurological Foundation of New Zealand Human Brain Bank (Department of Anatomy with Radiology, University of Auckland,
Auckland, New Zealand). The University of Auckland Human Subject Ethics Committee approved the protocols used in these studies. For further details see Waldvogel et al. (2006). Microtomecut brain sections of adult human brain were processed for immunohistochemical staining as previously described (Waldvogel et al., 2006). In brief, the human brains were fixed by perfusion through the basilar and internal carotid arteries, first with phosphate-buffered saline (PBS) with $1 \%$ sodium nitrite, followed by $15 \%$ formalin in $0.1 \mathrm{M}$ phosphate buffer, $\mathrm{pH}$ 7.4. After the perfusion, blocks were dissected out and kept in the same fixative for $24 \mathrm{~h}$. These blocks were cryoprotected in $20 \%$ sucrose in $0.1 \mathrm{M}$ phosphate buffer with $0.1 \% \mathrm{Na}$-azide for $2-3$ days, and then in $30 \%$ sucrose in $0.1 \mathrm{M}$ phosphate buffer with $0.1 \% \mathrm{Na}$-azide for a further $2-3$ days. Sectioning of the blocks was performed on a freezing microtome at a thickness of 50-70 $\mu \mathrm{m}$. The sections were collected in PBS with $0.1 \%$ sodium azide (PBS-azide) and stored for immunohistochemical processing.

\section{PRIMARY ANTIBODIES}

All antibodies used were dissolved in immunobuffer consisting of either $1 \%$ goat or $1 \%$ donkey serum in PBS with $0.2 \%$ Triton X-100 and $0.4 \%$ thimerosal (Sigma). Three different GlyR antibodies were tested for the detection of GlyRs in the human brain. These were:

(i) the mouse monoclonal antibody mAb4a raised against amino acids $96-105$ in the $48 \mathrm{kDa} \alpha 1$-subunit of the GlyR, and which also recognizes the $58 \mathrm{kDa} \beta$-subunit of the GlyR (Alexis Biochemicals; Pfeiffer et al., 1984; Schroder et al., 1991; Kirsch and Betz, 1993);

(ii) a mouse monoclonal antibody mAb2b raised against amino acids $1-10$ of the $48 \mathrm{kDa}$ GlyR $\alpha 1$ subunit (Alexis Biochemicals; Pfeiffer et al., 1984); and

(iii) a rabbit polyclonal antibody $\mathrm{AB} 5052$ (RGlyR) raised against a peptide from the N-terminus of human $\alpha 1$ GlyR subunit (sequence of the immunizing peptide is ARSTKPMSPSDFLDKLMGC; manufacturer's technical information) with cross reactivity to the $\alpha 2$ subunit (Chemicon, Temecula, CA, USA; Geiman et al., 2002). The rabbit polyclonal AB5052 was used mainly for double labeling studies (see below), and has been used reliably to label GlyR clusters in rat spinal cord and brainstem (Geiman et al., 2002; Liu and Wong-Riley, 2002; Rubio and Juiz, 2004), and human brain (Waldvogel et al., 2007).

The anti-GlyR antibodies used were directed to various different sequences of the GlyR subunits and detected either the $\alpha 1$ subunit only (mAb2b), the $\alpha 1$ and $\alpha 2$ subunits (AB5052), or recognized an epitope conserved in all known $\alpha$ and $\beta$ subunits (mAb4a; Pfeiffer et al., 1984; Schroder et al., 1991; Kirsch and Betz, 1993). The mAb4a and AB5052 antisera recognized the expected two protein bands ( 48 and $58 \mathrm{kDa}$ ) on Western blot of human basal ganglia tissue homogenates (Waldvogel et al., 2007). The staining patterns of the various GlyR antibodies were generally similar in the regions tested. The anti-GlyR antibodies produced similar patterns of staining except that the mAb4a which recognizes all subunits was consistently more intense than the other GlyR antibodies which selectively recognize $\alpha$ subunits. 
Other primary antibodies used to identify various cell phenotypes in the basal ganglia were as follows:

(1) Polyclonal rabbit anti-parvalbumin antiserum (SWANT, Bellinzona, Switzerland; PV-28, also named PV4064, manufacturer's information) was produced in rabbits immunized with rat muscle parvalbumin. The antiserum against parvalbumin was previously characterized by western blotting of mouse brain tissue (Schwaller et al., 2004; Collin et al., 2005), in which the serum recognized a single protein band of the appropriate molecular weight. The specificity of the polyclonal anti-parvalbumin antiserum was previously confirmed by absorption experiments using purified proteins and recombinant rat parvalbumin (Xu et al., 2006).

(2) Polyclonal rabbit anti-calretinin antiserum (SWANT, Bellinzona, Switzerland; 7699/4) was produced in rabbits immunized with recombinant human calretinin. The antiserum against calretinin was previously characterized by Western blotting of monkey and rat brain extracts (Schwaller et al., 1993), in which the serum recognized a single protein band of the appropriate molecular weight.

For the detection of gephyrin, the monoclonal mouse antibody $\mathrm{mAb} 3 \mathrm{~B} 11$ was used which was raised against the first half of gephyrin's E-domain (Synaptic Systems; Germany). The gephyrin antiserum recognized a single protein band $(93 \mathrm{kDa})$ on Western blot of rat brain (manufacturer's technical information), transfected gephyrin variants (Smolinsky et al., 2008), and human brain (Waldvogel et al., 2009) and stained a pattern of protein distribution in the human brain that is identical with previous reports (Baer et al., 2003; Waldvogel et al., 2003).

\section{SINGLE IMMUNOPEROXIDASE LABELING}

Using standard immunohistochemical procedures, adjacent series of sections were selected and processed free-floating in tissue culture wells. Sections were washed in PBS and $0.2 \%$ Triton X-100 (PBS-Triton) and pretreated for antigen retrieval using a protocol modified from that of Fritschy et al. (1998), before being processed for immunohistochemistry. Sections for antigen retrieval were transferred to six-well tissue culture plates and incubated overnight in $0.1 \mathrm{M}$ sodium citrate buffer, $\mathrm{pH} 4.5$, and transferred to $10 \mathrm{ml}$ of fresh sodium citrate buffer solution. Following this the sections were microwaved in a $650 \mathrm{~W}$ microwave oven for $30 \mathrm{~s}$ and allowed to cool before washing $(3 \times 15 \mathrm{~min}$ in PBS-Triton). The sections were then washed in PBS-Triton, incubated for $20 \mathrm{~min}$ in 50\% methanol and $1 \% \mathrm{H}_{2} \mathrm{O}_{2}$, washed again $(3 \times 15 \mathrm{~min})$ in PBS-Triton, and incubated in primary antibodies for 2-3 days on a shaker at $4^{\circ} \mathrm{C}$. The mouse monoclonal antibody $\mathrm{mAb} 2 \mathrm{~b}$ was used at dilution 1:2,000 and mouse monoclonal antibody mAb4a was used at a dilution of 1:2,000-1:5,000; the rabbit polyclonal antibody AB5052 (RGlyR) was used at a dilution of 1:500-1:1,000. The primary antibodies were washed off $(3 \times 15 \mathrm{~min}$; PBS-Triton) and the sections incubated overnight in species-specific biotinylated secondary antibodies (1:500; Sigma; Jackson Laboratories). The secondary antibodies were washed off $(3 \times 15 \mathrm{~min}$; PBS-Triton $)$ and the sections incubated for $4 \mathrm{~h}$ at room temperature in ExtrAvidin, 1:1,000 (Sigma). The sections were reacted in 0.05\% 3,3'-diaminobenzidine tetrahydrochloride (DAB; Sigma) and $0.01 \% \mathrm{H}_{2} \mathrm{O}_{2}$ in $0.1 \mathrm{M}$ phosphate buffer, $\mathrm{pH}$ 7.4, for 15-30 min to produce a brown reaction product. A nickel-intensified procedure was also used in which $0.4 \%$ nickel ammonium sulphate was added to the DAB solution to produce a blue-black reaction product (Adams, 1981). The sections were washed in PBS, mounted on gelatin chrom-alum coated slides, rinsed in distilled water, dehydrated through a graded alcohol series to xylene, and coverslipped with DPX (BDH, Poole, UK).

Routinely a few sections were processed as control sections to determine nonspecific staining using the same immunohistochemical procedures detailed above except that the primary antibody was omitted from the procedure. In addition, sections were stained for Nissl substance with Cresyl Violet according to standard techniques.

\section{IMMUNOFLUORESCENT DOUBLE LABELING}

For immunofluorescent double-labeling confocal laser scanning microscopy, sections were incubated in a cocktail of monoclonal and polyclonal antibodies (monoclonal antibody mAb4a diluted 1:2,000; polyclonal rabbit antibody AB5052 against GlyR subunits diluted 1:500; monoclonal mAb3B11 against gephyrin diluted 1:1,000; polyclonal rabbit antibody against parvalbumin diluted 1:500; polyclonal rabbit antibody against calretinin diluted 1:500). The sections were processed using the same procedure as the single-labeled sections. They were incubated in primary antibodies for 2-3 days on a shaker at $4^{\circ} \mathrm{C}$, washed, and then incubated in species-specific fluorescent secondary antibody directly linked to AlexaFluor 488 or AlexaFluor 594 (1:400; Molecular Probes) or CY3 (1:500). Control sections where the primary antibody was omitted showed no IR. The sections were washed, mounted on slides with Citifluor (Agar Scientific, Stanstead, UK) or ProLongGold (Invitrogen), and viewed using a Zeiss LSM510 or Leica SP2 confocal laser scanning microscope. Confocal laser scanning microscope digital images were collected and contrast optimized using Adobe Photoshop software. Linear methods were used to enhance image brightness and contrast for presentation, applied to all images with the same parameters unless otherwise indicated.

\section{GIYR-IMMUNOREACTIVITY (IR) IN THE HUMAN FOREBRAIN, BRAINSTEM, AND CERVICAL SPINAL CORD}

The principal aim of these studies was to immunohistochemically investigate the localization and distribution of GlyRs in the human forebrain, brainstem and cervical spinal cord at the regional and cellular levels. Sections from representative regions of the human brainstem and spinal cord were immunohistochemically labeled for GlyR subunits, and were microscopically examined to determine the distribution of specific immunoreactivities generated by these antibodies. Light and confocal laser scanning microscope analysis of the distribution of GlyR subunits revealed robust and punctate GlyR-IR in the human brainstem and spinal cord regions.

The antibodies assessed for these studies were selected to investigate the staining patterns of GlyRs based on their staining properties in human tissue. The GlyR monoclonal antibody mAb4a produced the strongest signal with the least background and was used for the majority of the GlyR staining in this study. It is predominantly the results of the antibodies mAb4a and mAb2b that are presented in this paper, although some illustrations from the polyclonal rabbit 
antibody AB5052 (termed RGlyR) are included where appropriate. The anti-GlyR antibodies demonstrated a similar distribution, although mAb4a consistently produced a stronger signal probably due to recognizing all subunits of the GlyR whereas the others selectively recognized $\alpha$ subunits.

When the staining pattern of single labeled adjacent sections was compared, the staining pattern of the three antibodies mAb4a, mAb2b and RGlyR was essentially the same at both the regional and cellular level (Figures 1 and 2). In double labeling studies where both the rabbit anti-GlyR antibody and the mAb4a antibody were incubated together, the staining pattern was very similar and showed an overlapping distribution on neuronal cell membranes (Waldvogel et al., 2007).

\section{GIyRs IN THE FIRST CERVICAL SEGMENT OF THE SPINAL CORD}

The labeling of GlyRs was consistently high throughout the cervical spinal cord (Baer et al., 2003; Waldvogel et al., 2009). GlyR-IR was evident throughout the gray matter of the spinal cord (Figures 1A,B) and was especially intense in the dorsal $(\mathrm{DH})$ and ventral horns (VH; Figures 1A,B). The neuropil of lamina II of the dorsal horn showed the most intense GlyR-IR in the spinal cord (Figures 1A,B). At high magnification a dense network of cell bodies and fine dendritic processes was evident with punctate GlyR-IR on their membranes in lamina II and III (Baer et al., 2003). In the ventral horn, moderate to high levels of intense GlyR puncta were observed on cell bodies and dendritic processes (Baer et al., 2003).

\section{GlyRs IN THE MEDULLA OBLONGATA}

GlyR-IR produced a heterogeneous distribution in the gray matter of the middle and lower medulla oblongata (Baer et al., 2003; Waldvogel et al., 2009). The hypoglossal nucleus labeled with high intensities of GlyR-IR, and the dorsal motor nucleus of the vagus nerve consistently showed moderate GlyR-IR (Baer et al., 2003). High levels of GlyR-IR were present in the spinal trigeminal nucleus; $\mathrm{Sp} 5 \mathrm{O}$ in the lower pons, $\mathrm{Sp} 5 \mathrm{C}$ in the lower medulla oblongata at the level of the pyramidal decussation (Figures 1C,D). The cuneate nucleus $(\mathrm{Cu})$ and the gracile nucleus ( $\mathrm{Gr}$ ) demonstrated small patches of high GlyR-IR (Figures 2C,D). At the cellular level a dense network of intensely labeled punctate GlyR-IR outlining small and large sized dendritic processes was observed in both of these nuclei (Baer et al., 2003). Similarly, neurons in the magnocellular region of the reticular formation in the medulla oblongata demonstrated GlyR-IR outlining the membranes of soma and processes (Figures $2 \mathrm{E}, \mathbf{F}$ ). The inferior olivary complex and the accessory olivary nuclei revealed moderate to high levels of GlyR-IR (Baer et al., 2003). At the cellular level, the inferior olivary complex and accessory olivary nuclei displayed high levels of punctate GlyR labeling on dendritic processes and neuronal cell bodies (Baer et al., 2003).

\section{GlyRs IN THE BASAL GANGLIA}

At low magnification the caudate nucleus $(\mathrm{CN})$ and putamen $(\mathrm{P})$ displayed a heterogeneous moderate to low level of labeling for GlyRs (Figures 1G,H) whilst the globus pallidus showed a relatively very low level of labeling (Waldvogel et al., 2007), and the substantia nigra $(\mathrm{SN})$ in the midbrain a relatively high level of labeling (Figures 1E,F). The caudate-putamen displayed a distinct heterogeneous pattern of staining with regions of very pale patches of
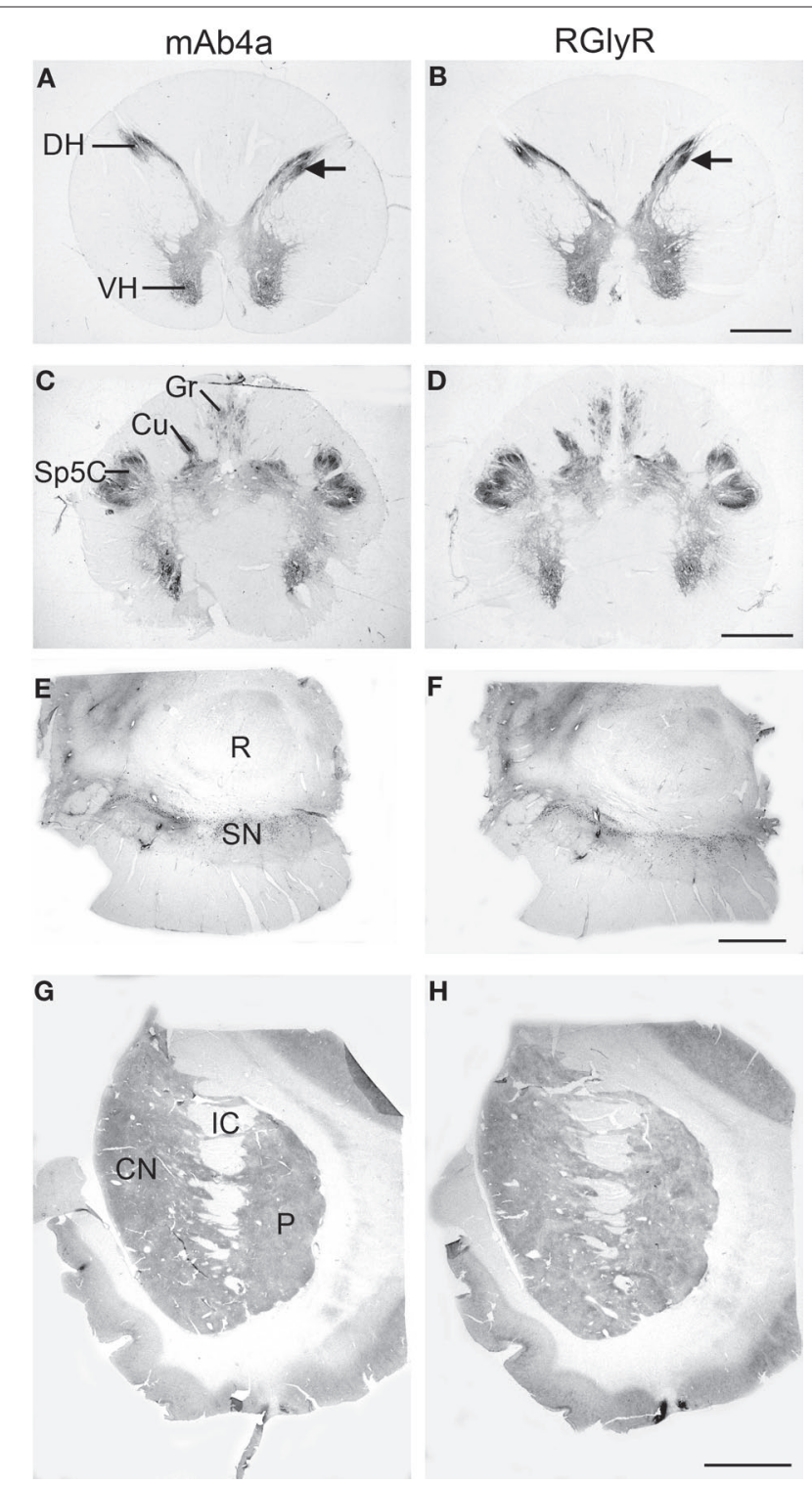

H

FIGURE 1 | Regional localization of glycine receptors at the cervical level of the human spinal cord $(A, B)$, pyramidal decussation in the lower medulla oblongata (C,D), substantia nigra (E,F) and basal ganglia at the level of the caudate-putamen $(G, H)$ visualized by DAB staining of adjacent sections using monoclonal antibody mAb4a $(A, C, E, G)$ and rabbit polyclonal antibody AB5052 (B,D,F,H). (A,B) Light macroscopic images of sections of the first cervical segment of the spinal cord stained for GlyR with mAb4a (A) and AB5052 (B) antibody showing especially intense labeling in lamina II of the dorsal horn (DH) and moderate to high levels of GlyR-IR in the gray matter of the ventral horn $(\mathrm{VH})$ and dorsal horn. (C,D) Macroscopic images of sections of the pyramidal decussation stained for GlyR with mAb4a (C) and AB5052 (D) antibody revealing patchy GlyR-IR in the gracile nucleus (Gr) and the cuneate nucleus $(\mathrm{Cu})$ and intense GlyR-IR in the spinal trigeminal nucleus (Sp5C). (E,F) Macroscopic images of sections of the substantia nigra (SN) stained for GlyR with mAb4a (G) and AB5052 (H) antibody showing high levels of GlyR-IR in the regions of the substantia nigra pars compacta and the substantia nigra pars reticulata. $(\mathbf{G}, \mathbf{H})$ Macroscopic images of sections of the basal ganglia at the level of the caudate-putamen stained for GlyR with mAb4a (E) and AB5052 (F) antibody suggesting a heterogeneous distribution of GlyR in the caudate nucleus (CN) and putamen (P) separated by the internal capsule (IC). Scale bar = $2 \mathrm{~mm}$ in (A,B); $2.5 \mathrm{~mm}$ in (C,D); $0.5 \mathrm{~cm}$ in (E-H). 

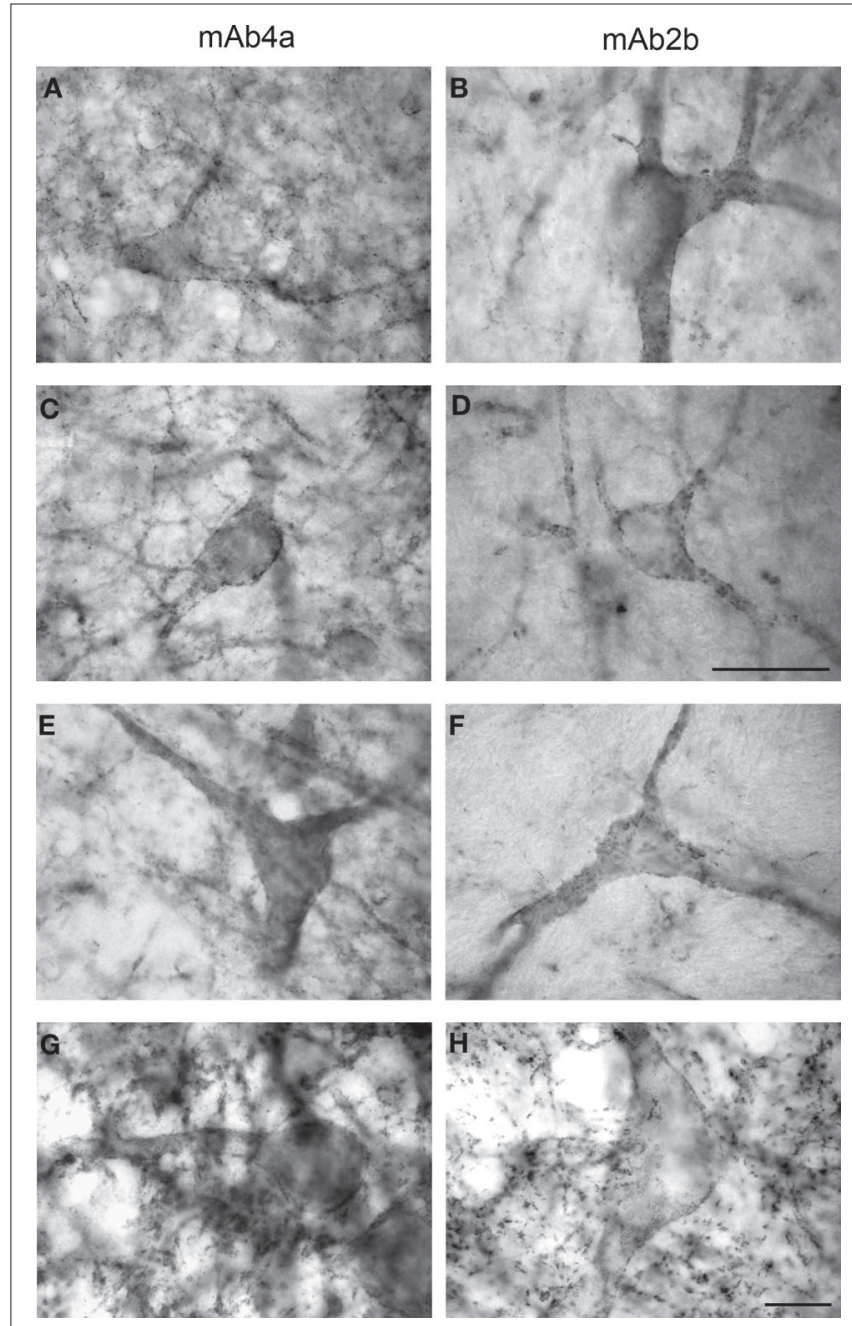

FIGURE 2 | Glycine receptor labeling on neurons in the human midbrain and medulla oblongata visualized by DAB staining of adjacent sections using monoclonal antibody $m A b 4 a(A, C, E, G)$ and monoclonal antibody $\mathbf{m A b 2 b}(\mathbf{B}, \mathbf{D}, \mathbf{F}, \mathbf{H})$. (A,B) Neurons in the periaqueductal grey area of the midbrain showing high levels of punctate GlyR-IR along their soma and processes, revealing similar IR patterns using mAb4a (A) or mAb2b

(B). (C,D) Neurons in the superior colliculus of the midbrain immunoreactive for mAb4a (C) and mAb2b (D) demonstrating GlyR-IR outlining the membranes of soma and processes. (E,F) Neurons in the magnocellular region of the reticular formation in the medulla oblongata immunoreactive for mAb4a (E) and mAb2b (F) revealing GlyR-IR along the neuronal soma and processes. (G,H) High levels of immunoreactive GlyR are present on neurons in the hypoglossal nucleus of the upper medulla stained for $m A b 4 a(\mathbf{G})$ and $m A b 2 b$ (H). Scale bar $=50 \mu \mathrm{m}$ in (D) applies to (C-F); $10 \mu \mathrm{m}$ in $\mathbf{H}$ [applies to $(\mathbf{A}, \mathbf{B}, \mathbf{G}, \mathbf{H})$ ].

staining surrounded by a more densely staining background which resembled the striosome and matrix compartmental organization of the striatum (Figures 1G,H).

Neurons in both the pars compacta and pars reticulata regions of the substantia nigra were immunoreactive for GlyRs. Both the mAb4a and RGlyR antibodies stained most intense on the pars reticulata neurons and less intense on the pigmented pars compacta neurons (Figures 1E,F; Waldvogel et al., 2007). In the substantia nigra pars compacta intense IR was localized in the region of the pigmented neurons (Waldvogel et al., 2007) and was observed on both the cell bodies and primary dendrites of pigmented neurons. The distal dendrites of SNc neurons did not appear to be immunolabeled (Waldvogel et al., 2007). The IR in the pars compacta region often highlighted groups of pigmented neurons scattered mainly throughout the dorsal tier. On closer inspection, not all pigmented neurons were coated with GlyRs and counts of the pigmented neurons indicated that approximately $80 \%$ of the pigmented neurons in the substantia nigra pars compacta showed IR for either mAb4a or RGlyR on their cell membranes (Waldvogel et al., 2007).

The large neurons of the substantia nigra pars reticulata $(\mathrm{SNr})$ that were intensely labeled by GlyRs had elongated cell bodies approximately $30-\mu \mathrm{m}$ long with long branching dendrites often with a bipolar orientation (Waldvogel et al., 2007). SNr neurons were generally more intensely labeled for GlyRs than the substantia nigra pars compacta neurons. High-resolution confocal laser scanning microscopy revealed that the GlyRs were localized in clusters; the clusters were often conspicuously arranged in discrete circular patterns on the cell surface membranes of the soma and proximal dendrites of the pars compacta and pars reticulata neurons and proximal dendrites (Waldvogel et al., 2007).

At the cellular level, neurons in the periaqueductal grey area (Figures 2A,B) and the superior colliculus (Figures 2C-F) of the human substantia nigra demonstrated GlyR-IR on the cell surface membranes of the soma and proximal dendrites. In agreement with previous reports (Baer et al., 2003), GlyR 'hot spots' were detected (Figures 2 and 3).

\section{GlyRs AND GEPHYRIN}

We have shown previously that gephyrin is ubiquitously distributed in the human brain (Waldvogel et al., 2003) and associated with GlyRs in the human brainstem (Baer et al., 2003). Gephyrin-IR was observed in sections at the first cervical segment of the human spinal cord (Figures 3H,K). Gephyrin- and GlyR-IR was evident throughout the gray matter of the spinal cord and was especially intense in the dorsal and ventral horns (Figures 1A,B; Baer et al., 2003; Waldvogel et al., 2009). At high magnification a dense network of cell bodies and fine dendritic processes was evident with punctate gephyrin- and GlyR-IR on their membranes in lamina I, II and III (Figures 3G-L; Baer et al., 2003). Table 1 illustrates the relative intensity of GlyR-IR and gephyrin-IR in the human medulla oblongata and spinal cord (Baer et al., 2003; Waldvogel et al., 2009).

\section{CHEMICAL CHARACTERISTICS OF GIYR IMMUNOREACTIVE NEURONS IN THE HUMAN BASAL GANGLIA}

Various markers were used to determine the chemical phenotype of cells that displayed GlyR IR in the basal ganglia (Waldvogel et al., 2007). Double labeling immunohistochemical studies were performed using markers to striatal interneurons: cholineacetyltransferase, parvalbumin, calretinin and neuropeptide $Y$ in order to further characterize which striatal interneurons had GlyRs on their surface membranes (Waldvogel et al.,2007). The substantia nigra pars compacta neurons were recognized by their neuromelanin pigmentation.

Previously, six different types of neurons were identified in the striatum on the basis of cellular and dendritic morphology, chemical neuroanatomy, and $\mathrm{GABA}_{\mathrm{A}}$ receptor subunit configuration 

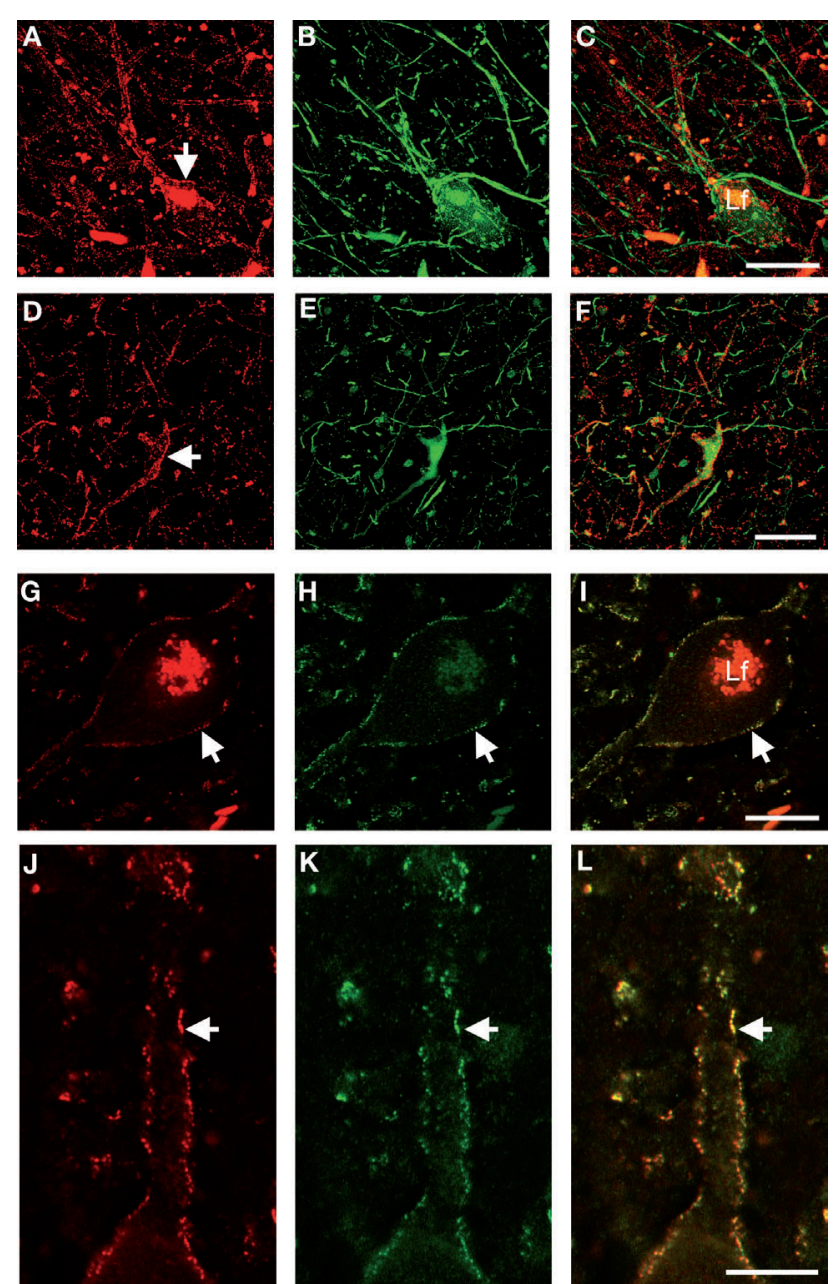

FIGURE 3 | High-resolution confocal laser scanning microscopy images of neurons in the substantia nigra pars reticulata (A-C), putamen (D-F), and first cervical segment of the spinal cord (G-L) of the human CNS double-labeled for GlyR (left column) and other cell markers (middle column) with combined images shown in the right column. (A-C) Neuron in the substantia nigra pars reticulata is labeled red for GlyR [mAb4a in (A), arrow] and immunopositive for rabbit anti-parvalbumin [green in (B)], green unlabeled parvalbumin processes in the picture resemble axon bundles, combined images in (C). (D-F) Neuron in the putamen that is outlined with GlyR-IR [mAb4a, red in (D), arrow] is labeled with rabbit anticalretinin immunoreactivity [green in (E)], combined images in (F). (G-I) Large neuron in the spinal cord that is outlined with rabbit anti-GlyR immunoreactivity [red in (G)] is labeled with mouse anti-gephyrin immunoreactivity [green in (H)], combined images in (I). Note the high degree of overlap of both markers, exemplified by the arrow highlighting the colocalized IR patterns. (J-L) High magnification of a process of a large motoneuron in the cervical spinal cord that shows punctate GlyR-IR [red in (J)] and punctate gephyrin-IR [green in (K)] demonstrating the high degree of colocalization of the GlyR and gephyrin IR patterns [yellow in (L)]. Lf in (C) and (I) indicates lipofuchsin autofluorescence in the cell body. Scale bar $=25 \mu \mathrm{m}$ in (C) [applies to (A-C)], (F) [applies to (D-F)]; (G) [applies to (G-I)], and (J) [applies to (J-L)].

(Waldvogel et al., 1999). We determined that GlyRs are localized predominantly to interneurons characterized neurochemically by IR for three of these six striatal neuron types (cholineacetyltransferase, parvalbumin, or calretinin; Waldvogel et al., 2007). Only very few
Table 1 | Relative intensity of GlyR-IR and gephyrin-IR in the human medulla oblongata and spinal cord.

\begin{tabular}{lll}
\hline Brain region & GlyR-IR & Gephyrin-IR \\
\hline Dorsal motor nucleus of the vagus nerve & ++ & ++ \\
Hypoglossal nucleus & $+H+$ & ++ \\
Solitary nucleus & ++ & ++ \\
Gracile nucleus & ++ & ++ \\
Spinal trigeminal nucleus & +++ & ++ \\
Accessory olivary nuclear complex & +++ & +++ \\
Inferior olive & +++ & ++ \\
Lateral reticular nucleus & ++ & +++ \\
Spinal cord lamina II & +++ & ++ \\
Spinal cord dorsal horn & +++ & ++ \\
Spinal cord ventral horn & ++1 &
\end{tabular}

+ , weak levels of IR; ++, moderate levels of IR;+++ high levels of IR;++++, most intense levels of IR.

of the striatal GlyR-IR positive neurons were double labeled with parvalbumin, corresponding to type (i) neurons (Figures 3A-C; Waldvogel et al., 2007).

Previously we demonstrated that the globus pallidus has a mixed population of GlyR positive neurons that may represent different types of interneurons and possibly includes a subpopulation of the projection neurons (Waldvogel et al., 2007). Small numbers of GlyR positive pallidal neurons were labeled with parvalbumin or calretinin (Figures 3D-F). Most neurons in the human globus pallidus are labeled with parvalbumin or calretinin (Waldvogel et al., 1999), therefore the low number of the GlyRs positive neurons double labeled with parvalbumin or calretinin would suggest they are not projection neurons, but may be local interneurons (Waldvogel et al., 2007).

\section{CONTEXTUAL SUMMARY OF IMMUNOHISTOCHEMICAL FINDINGS}

Using immunohistochemical methods at the light and confocal laser scanning microscopic levels, our results suggest that GlyRs are widely distributed in the human forebrain, brainstem, and cervical spinal cord. The methods used were optimized for structural tissue preservation and receptor stability of the postmortem human brain to limit background staining and lipofuscin artifacts (Waldvogel et al., 2006).

\section{ANTIBODY CHARACTERIZATION}

It is established that mAb2b-and 4a-IR represent postsynaptic structures (Triller et al., 1985; Altschuler et al., 1986) and also intracellular sites of GlyR protein synthesis, transport and aggregation (Hoch et al., 1989). Sequence comparison of human and rat GlyR cDNAs reveals a complete conservation of the epitope for the mAb4a antibody (Schroder et al., 1991). In rat brain, Mab4a produces both punctate and diffuse somatic labeling, suggesting that the Mab4a antigens are not restricted to postsynaptic membrane specializations (Kirsch and Betz, 1993). GlyR, using mAb4a, has demonstrated localization of GlyR at postsynaptic sites on human cortical neurons (Naas et al., 1991). Intracellular labeling was also reported for the anti-GlyR AB5052 (Geiman et al., 2002). 
Although the receptor clusters are mainly postsynaptic a proportion of extrasynaptic and cytoplasmic staining is observed (Levi et al., 1999; Dumoulin et al., 2000). Using the antibodies Mab2b, Mab4a, and AB5052, it is not possible to exclusively detect the GlyR $\beta$ subunit, which contains the gephyrin binding domain (Meyer et al., 1995) or to differentiate between $\alpha 2$ and/or $\alpha 3$ subunitcontaining GlyRs. To establish whether gephyrin is only associated with $\beta$ subunit containing GlyRs in human brain, differential studies using $\beta, \alpha 2$ and $\alpha 3$ subunit-specific antibodies are required. These additional GlyR subunit-specific antibodies are not yet available.

\section{DISTRIBUTION OF GIYRS IN THE FOREBRAIN, BRAINSTEM, AND CERVICAL SPINAL CORD OF THE HUMAN BRAIN}

The major findings in this study are that GlyRs are highly expressed on various subpopulations of neurons in the different nuclei of the forebrain, brainstem, and cervical spinal cord of the human brain (Baer et al., 2003; Waldvogel et al., 2007, 2009). In the forebrain, GlyR IR is most abundant in the substantia nigra, and is found on particular interneuronal cell types in the striatum (Waldvogel et al., 2007). Furthermore, GlyR-IR was detected scattered throughout the globus pallidus and substantia nigra, and was also localized to medullary laminae regions surrounding the two segments of the globus pallidus.

At the regional level, the most intense staining was observed in the dorsal and ventral horns of the spinal cord, the spinal trigeminal nuclear complex, and the motor nuclei associated with the autonomic nervous system such as the dorsal motor nucleus of the vagus nerve and motor cranial nerve nuclei such as the hypoglossal nucleus. These areas revealed intense GlyR labelling and therefore glycinergic inhibitory control of this nucleus is intense and possibly predominant. The patches of high IR in the cuneate and gracile nuclei may be associated with particular sensory inputs as the inputs to these nuclei are all topographically organized (Baer et al., 2003). Other brainstem nuclei such as the inferior olivary complex displayed moderate to high levels of GlyR-IR (Waldvogel et al., 2007).

The substantia nigra contained the highest levels of GlyR-IR in the human basal ganglia. High levels were observed in the region of the substantia nigra pars compacta. On closer investigation the GlyR-IR was localized on pigmented neurons and dendritic processes in the substantia nigra pars compacta region. Approximately $80 \%$ of the pigmented neurons had GlyRs located on their cell bodies and proximal dendrites. This would suggest that a large number of dopaminergic neurons possess GlyRs. This may indicate that the dopaminergic neurons of the substantia nigra pars compacta may be divided into different subgroups depending on the various receptor types which are expressed on their cell membranes (Waldvogel et al., 2007). The neurons of the substantia nigra pars reticulata were intensely reactive for GlyRs. These were large rounded or elongated neurons with long branching neurons characteristic of the large projection neurons of the substantia nigra pars reticulata. In the human striatum, GlyRs are localized predominantly to interneurons characterized neurochemically by IR for three of these six striatal neuron types (choline acetyltransferase, parvalbumin, or calretinin) (Waldvogel et al., 2007).

\section{CELLULAR AND SUBCELLULAR GIyRs LOCALIZATION}

At the cellular level, GlyR-IR was present on the plasma membranes of the soma and dendrites of neurons throughout the human substantia nigra, pons, medulla oblongata and cervical spinal cord (Baer et al., 2003; Waldvogel et al., 2007, 2009). Using light microscopy, punctate labeling for GlyRs was observed on the membranes of neuronal somata and processes.

Confocal laser scanning microscopy revealed GlyR 'hot spots' (brightly stained puncta) reflecting synaptic localization and aggregation (Grunert and Wassle, 1993; Kirsch et al., 1996). The confocal laser scanning microscopy data in the human are consistent with GlyRs as observed in rat spinal cord (Geiman et al., 2002). In addition to GlyR cluster 'hot spots,' GlyR-IR was observed along the entire length of neuronal membranes. A similar observation was reported for cat spinal cord ventral horn neurons where the density and topographical organization of GlyR clusters varied in different neuronal types and in different dendritic regions (Alvarez et al., 1997).

\section{COMPARING THE DISTRIBUTION OF GIYRs IN HUMAN AND RODENT BRAINSTEM AND SPINAL CORD}

The current data show that the general distribution of GlyR subunits detected in the human rostral and caudal pons, rostral medulla oblongata and the cervical spinal cord are generally in good agreement with immunohistochemical and immunoenzymatic electron microscopy studies in the rat brainstem and spinal cord (Triller et al., 1985, 1987; van den Pol and Gorcs, 1988; Rampon et al., 1996; Alvarez et al., 1997; Geiman et al., 2002). The subcellular distribution of GlyRs in the mammalian retina has also been examined (Wässle et al., 1998). Using in situ hybridization techniques, GlyR mRNAs were detected in somata and dendrites of most neurons of the ventral horn of rat spinal cord (Racca et al., 1997); and in the rat spinal trigeminal nucleus, principal trigeminal nucleus, gracile and cuneate nuclei (Sato et al., 1991). Another rat brain study showed high levels of IR for the neurotransmitter glycine in the hypoglossal nucleus, gracile nucleus, spinal trigeminal nucleus and raphe nucleus (Rampon et al., 1996). The GlyR-IR which we have detected in the human is in agreement with these studies in the rat brain (Table 2 ).

\section{GEPHYRIN INVOLVEMENT}

Numerous studies have revealed that gephyrin is present at glycinergic and GABAergic synapses (Fritschy et al., 2008). Virtually complete colocalization of GlyR-IR and postsynaptic gephyrin-IR has been established in the ventral horn of rat spinal cord (Triller et al., 1985, 1987; Todd et al., 1995, 1996; Colin et al., 1998). Another study suggested that most GlyRs in the rabbit retina colocalize with gephyrin (Zucker, 1998). Previously we demonstrated that gephyrin is widely distributed in the human brain and spinal cord, and that a large proportion of the GlyRs in the brainstem and spinal cord show punctate IR that co-localizes with gephyrin (Baer et al., 2003; Waldvogel et al., 2003, 2009). The studies reviewed here establish the association of gephyrin and GlyRs in human brainstem and spinal cord indicating an association of gephyrin and GlyRs, implicating similar functions for gephyrin in human brain as that reported for rodent brain. Thus, gephyrin is likely to play a fundamental role in the organization of major types of inhibitory synapses at postsynaptic membranes in human brain. 
Table 2 | Comparison of the distribution of relative intensity of GlyR-IR in human and rodent brainstem and spinal cord (van den Pol and Gorcs, 1988; Rampon et al., 1996; Baer et al., 2003).

\begin{tabular}{|c|c|c|c|c|}
\hline Brain region & $\begin{array}{l}\text { GlyR-IR on cell } \\
\text { bodies in human }\end{array}$ & $\begin{array}{l}\text { GlyR-IR on processes } \\
\text { in human }\end{array}$ & $\begin{array}{l}\text { GlyR-IR on cell } \\
\text { bodies in rodent }\end{array}$ & $\begin{array}{l}\text { GlyR-IR on } \\
\text { fibers in rodent }\end{array}$ \\
\hline Dorsal motor nucleus of the vagus nerve & + & $+1+$ & 0 to + & + \\
\hline Solitary nucleus & + & + & + & H \\
\hline Gracile nucleus & $+1+$ & $+1+$ & ++ & $H+$ \\
\hline Locus coeruleus & + & $+1+$ & 0 to + & $+1+$ \\
\hline Dorsal raphe nucleus & $H$ & ++ & 0 to + & + \\
\hline Accessory olivary nuclear complex & + & H+1 & +H+ & H+1 \\
\hline Inferior olive & $H+$ & H+ & +++ & H+ \\
\hline Lateral reticular nucleus & + & + & ++ & $+H$ \\
\hline
\end{tabular}

0 , no detectable IR; +, weak levels of IR; ++, moderate levels of IR; +++ high levels of IR; ++++, most intense levels of IR.

Studies in rodents have revealed that gephyrin directly interacts with key regulators of microfilament dynamics, namely profilin I and IIa and microfilament adaptors of the mammalian enabled (Mena)/vasodilator stimulated phosphoprotein (VASP) family (Giesemann et al., 2003). This interesting link may play an important role in receptor density and dynamics at inhibitory synapses including activity-dependent remodeling of synaptic structures (Neuhoff et al., 2005). Although the scenario in human CNS is not known, high-resolution microscopy analysis suggested that not all GlyR $\alpha 1$ subunit-IR co-localizes with gephyrin, indicating that there may be other mechanisms involved in GlyR localization, presumably at presynaptic or extrasynaptic sites. The distribution of other major GlyR subtypes in human brain $(\alpha 2, \alpha 3)$ remains to be determined.

Recent exciting data revealed that gephyrin and the cell adhesion molecule neuroligin 2 interact and that deletion of neuroligin 2 in mice disturbs glycinergic synaptic transmission (Poulopoulos et al., 2009). Neuroligins are important for the assembly of synaptic specializations, and complexes of neuroligin 2, gephyrin and collybistin are sufficient for cell-autonomous clustering of inhibitory neurotransmitter receptors (Poulopoulos et al., 2009). The role of neuroligins at inhibitory synapses in the human CNS requires further attention, but these recent findings in rodents demonstrate that neuroligins can be regarded as important organizer proteins at postsynaptic glycinergic synapses.

Furthermore, gephyrin has multiple functions and is required for the biosynthesis of molybdenum cofactor (Feng et al., 1998; Fritschy et al., 2008). In an extensive search for human gephyrin transcript heterogeneity, we identified neuronal gephyrin isoforms created from the alternative splicing of five exons, also termed cassettes $(\mathrm{C} 3, \mathrm{C} 4 \mathrm{~A}-\mathrm{D})$ in the central linker region of the protein (Rees et al., 2003). The biological role of these gephyrin isoforms is not clear. At least one of these variants (cassette C3) is constitutively spliced into non-neuronal gephyrin (Rees et al., 2003), but otherwise the biological role of this neuronal heterogeneity is unclear. This is particularly true since most known interactors of gephyrin, including GlyR $\beta$, profilins, Mena/VASP (Giesemann et al., 2003) and collybistin (Harvey et al., 2004) all bind to the Cterminal MoeA homology domain. One hypothesis is that gephyrin cassettes may create or destroy sites for additional protein-protein interactions, perhaps controlling the accumulation of specific signalling pathways or cytoskeletal interactions in a brain-region specific manner. Also, these isoforms might play a role in GlyR clustering and/or might be differentially expressed during development and/or in healthy versus diseased brain tissue. In addition, defined gephyrin isoforms might be selectively distributed to synaptic or extrasynaptic sites and/or might be enriched at glycinergic synapses. Future work will elucidate whether gephyrin-/GlyR-IR patterns are changed by neuropathological disorders, and whether these IR patterns could represent novel biomarkers or indicators for neurodegenerative disease processes, by comparing and contrasting the immunoreactive patterns observed between normal and neuropathological brain samples. Also, given the limitations of immunoreactive approaches, future work will evaluate the development of other technology platforms (for example, Quantum dot nanotechnologies) to enhance detection specificity for GlyR.

\section{FUNCTIONAL CONTEXT AND LINKAGES}

The source of the neurotransmitter glycine which presumably acts on the GlyRs found in the human basal ganglia is not clear, but studies in the rat show that glycinergic IR terminals are present in regions of the ventral pallidum and basal forebrain (Rampon et al., 1996). This may indicate that other regions of the basal ganglia such as the lateral medullary lamina between the putamen and external segment of the globus pallidus and the medial medullary lamina between the external segment of the globus pallidus and internal segment of the globus pallidus examined previously (Waldvogel et al., 2007) in the human basal ganglia may also be innervated by 
glycinergic neurons. Since the greatest concentration of glycine and GlyRs are predominantly found in the brainstem it is possible that nuclei in the brainstem may be the source of the glycinergic input to the basal ganglia.

Our findings, consistent with findings in the rat (Darstein et al., 2000), suggest that GlyRs are found on cholinergic interneurons in the human striatum (Waldvogel et al., 2007). Functional studies in the rat striatum have demonstrated that GlyRs can be activated within the striatum and that glycine application can induce acetylcholine release in the striatum (Darstein et al., 1997, 2000). Therefore the same mechanism may also operate in the human striatum. In addition, dopamine can be released in the striatum by application of glycine (Yadid et al., 1993) and is blocked by strychnine. Also, strychnine-sensitive glycinergic responses have been recorded in the rat striatum on both large cholinergic neurons and on GABAergic medium spiny neurons. One study has also established that ethanol can inhibit glycine induced responses in the rat striatum (Darstein et al., 1997), suggesting that glycine might present a new site for the functional effect of alcohol.

The pharmacological and physiological role of glycine in the substantia nigra is still unclear but studies in rats and cats have identified various effects of glycine in the substantia nigra including depression of dopamine neuron activity and reduced efflux of dopamine in the caudate nucleus (Cheramy et al., 1978; de Montis et al., 1982). In contrast, other studies demonstrated an increase of dopamine efflux in the substantia nigra with glycine application (Kerwin and Pycock, 1979), as well as glycine mediated effects of GABA transmission in the VTA region (Ye et al., 2004). Another study has implicated the role of glia as being a source of extracellular glycine which can act on GlyRs in the substantia nigra pars reticulata (Dopico et al., 2006).

Defects in mammalian glycinergic neurotransmission at post and presynapse can result in a paroxysmal motor disorder, hyperekplexia (for review see Harvey et al., 2008), and the GlyR alpha3 subunit is an essential target for inflammatory pain sensitization (Harvey et al., 2004). However, the locations of GlyR subunit combinations in human adult brain and spinal cord remain largely uncharacterized (Naas et al., 1991), and the biological and genetic basis of many cases of hyperekplexia and paroxysmal movement disorders remain unresolved. In addition, there is little data evaluating the GlyR and glycine presence in neurodegenerative diseases. Although GlyRs are changed in some pathological conditions (e.g. in the substantia nigra in Parkinson's disease), the neuropharmacology of the glycine system is still poorly understood (Lloyd et al., 1983). Moreover, glycine concentrations in Huntington's disease

\section{REFERENCES}

Adams J. C. (1981). Heavy metal intensification of DAB-based HRP reaction product. J. Histochem. Cytochem. 29, 775.

Altschuler, R.A., Betz, H., Parakkal, M. H., Reeks, K. A., and Wenthold, R. J. (1986). Identification of glycinergic synapses in the cochlear nucleus through immunocytochemical localization of the postsynaptic receptor. Brain Res. 369, 316-320.
Alvarez,F.J.,Dewey, D.E., Harrington, D. A., and Fyffe, R.E.(1997).Cell-type specific organization of glycine receptor clusters in the mammalian spinal cord. J. Comp. Neurol.379, 150-170.

Andrew, M., and Owen, M. J. (1997). Hyperekplexia: abnormal startle response due to glycine receptor mutations. Br. J. Psychiatry 170, 106-108.

Baer, K., Waldvogel, H. J., During, M. J., Snell, R. G., Faull, R. L. M., and Rees, M. I. (2003). Association of

patients were higher compared to controls as reported for analysis of platelets (Reilmann et al., 1997), and cerebrospinal fluid (Nicoli et al., 1993). It is not known which metabolic defect might be responsible for the changes in glycine levels in Huntington's disease, but the link to the $N$-methyl-D-aspartate subclass of ionotropic glutamate receptors (NMDARs), which possess a glycine binding site, and NMDARs excitoxicity in Huntington's disease has been suggested (Reilmann et al., 1997; Fan and Raymond, 2007).

Finally, the need to increase our understanding of neuroinhibitory receptor distribution and function including GlyRs in healthy and diseased human brain tissue is reflected in the potential to create new pharmacological drugs for different neuropsychiatric disorders based on agonist activity at inhibitory neurotransmitter receptors. In summary, we provide evidence for the localization of GlyRs in neuronal populations in various regions throughout the human forebrain, brainstem, and cervical spinal cord. GlyRs are localized especially on cholinergic and calretinin positive neurons in the striatum and globus pallidus, as well as in high concentrations within the intermedullary laminae of the globus pallidus and the substantia nigra. High levels of GlyRs are also found throughout the substantia nigra where previous studies have implicated GlyRs in the modulation of dopaminergic function. It is postulated from previous studies that glycinergic mechanisms that act on glycine ion channel receptors are involved in the modulation of cholinergic, dopaminergic and GABAergic pathways in the basal ganglia. Further studies are required to establish GlyR heterogeneity in human brain using additional subunit-specific anti-GlyR antibodies. The clustering protein gephyrin directly interacts with GlyRs, and the role of gephyrin and its isoforms remains elusive with regard to the mechanisms of synaptic localization, dynamic receptor clustering and GlyR heterogeneity in human brain. Future studies are essential for establishing the biological context and basic neuroscience principles of human glycinergic neuroinhibition in normal and neuropathological conditions.

\section{ACKNOWLEDGMENTS}

This work was supported by grants from the Neurological Foundation of New Zealand, the Health Research Council of New Zealand and the Wales Epilepsy Research Network. We thank the Neurological Foundation of New Zealand Human Brain Bank for providing the human brain tissue used in these studies. We also thank the Biomedical Imaging Research Unit (BIRU) in the Department of Anatomy with Radiology, University of Auckland for expert assistance. Kristin Baer is grateful for support from the Royal Society.

gephyrin and glycine receptors in the human brainstem and spinal cord: an immunohistochemical analysis. Neuroscience 122, 773-784.

Bakker, M. J., van Dijk, J. G., van den Maagdenberg, A. M., and Tijssen, M. A. (2006). Startle syndromes. Lancet Neurol. 5, 513-524.

Cascio, M. (2002). Glycine receptors: lessons on topology and structural effects of the lipid bilayer. Biopolymers 66, 359-368.
Cheramy, A., Nieoullon, A., and Glowinski, J. (1978). Inhibition of dopamine release in the cat caudate nucleus by nigral application of glycine. Eur. J. Pharmacol. 47, 141-147.

Colin, I., Rostaing, P., Augustin, A., and Triller, A. (1998). Localization of components of glycinergic synapses during rat spinal cord development. J. Comp. Neurol. 398, 359-372.

Collin, T., Chat, M., Lucas, M. G., Moreno, H., Racay, P., Schwaller, B., 
Marty, A., and Llano, I. (2005). Developmental changes in parvalbumin regulate presynaptic $\mathrm{Ca}^{2+}$ signaling. J. Neurosci. 25, 96-107.

Colquhoun, D., and Sivilotti, L. G. (2004). Function and structure in glycine receptors and some of their relatives. Trends Neurosci. 27, 337-344.

Connolly, C. N., and Wafford, K.A. (2004). The Cys-loop superfamily of ligandgated ion channels: the impact of receptor structure on function. Biochem. Soc. Trans. 32(Pt3), 529-534.

Danober, L., and Pape, H. C. (1998). Strychnine-sensitive glycine responses in neurons of the lateral amygdala: an electrophysiological and immunocytochemical characterization. Neuroscience 85, 427-441.

Darstein, M., Landwehrmeyer, G. B., Kling, C., Becker, C. M., and Feuerstein, T. J. (2000). Strychninesensitive glycine receptors in rat caudatoputamen are expressed by cholinergic interneurons. Neuroscience 96, 33-39.

Darstein, M., Loschmann, P.A., Knorle, R., and Feuerstein, T.J. (1997). Strychninesensitive glycine receptors inducing $[3 \mathrm{H}]$-acetylcholine release in rat caudatoputamen: a new site of action of ethanol? Naunyn Schmiedebergs Arch. Pharmacol. 356, 738-745.

de Montis, G., Beuamont, K., JavoyAgid, F., Agid, Y., Constantidinidis,J., Lowenthal, A., and Lloyd, K. G. (1982). Glycine receptors in the human substantia nigra as defined by $[3 \mathrm{H}]$ Strychnine binding. J. Neurochem. 38, 718-724.

den Eynden, J. V., Ali, S. S., Horwood, N., Carmans, S., Brône, B., Hellings, N., Steels, P., Harvey, R. J., and Rigo, J. M. (2009). Glycine and glycine receptor signalling in non-neuronal cells. Front. Mol. Neurosci. 2, 9.

Dopico, J. G., Gonzalez-Hernandez, T., Perez, I. M., Garcia, I. G., Abril, A. M., Inchausti,J.O., and Rodriguez Diaz, M. (2006). Glycine release in the substantia nigra: interaction with glutamate and GABA. Neuropharmacology 50, 548-557.

Dudeck, O., Lübben, S., Eipper, S., Knörle, R., Kirsch, M., Honegger, J., Zentner, J., and Feuerstein, T.J. (2003). Evidence for strychnine-sensitive glycine receptors in human amygdala. Naunyn Schmiedebergs Arch. Pharmacol. 368, 181-187.

Dumoulin, A., Levi, S., Riveau, B., Gasnier, B., and Triller, A. (2000). Formation of mixed glycine and GABAergic synapses in cultured spinal cord neurons. Eur. J. Neurosci. 12, 3883-3892.

Fan, M. M., and Raymond, L. A. (2007). $\mathrm{N}$-methyl-D-aspartate (NMDA) receptor function and excitotoxicity in
Huntington's disease. Prog. Neurobiol. 81, 272-293.

Feng, G., Tintrup, H., Kirsch, J., Nichol, M. C., Kuhse, J., Betz, H., and Sanes, J. R. (1998). Dual requirement for gephyrin in glycine receptor clustering and molybdoenzyme activity. Science 282, 13211324

Flint, A. C., Liu, X., and Kriegstein, A. R. (1998). Nonsynaptic glycine receptor activation during early neocortical development. Neuron 20, 43-53.

Fritschy, J. M., Harvey, R. J., and Schwarz, G. (2008). Gephyrin: where do we stand, where do we go? Trends Neurosci. 31, 257-264.

Fritschy, J. M., Weinmann, O., Wenzel, A., and Benke, D. (1998). Synapse-specific localization of NMDA and GABA(A) receptor subunits revealed by antigenretrieval immunohistochemistry. J. Comp. Neurol. 390, 194-210.

Geiman,E. J., Knox,M.C., and Alvarez, F. J. (2000). Postnatal maturation of gephyrin/glycine receptor clusters on developing Renshaw cells. J. Comp. Neurol. 426, 130-142.

Geiman, E. J., Zheng, W., Fritschy, J. M., and Alvarez, F. J. (2002). Glycine and $\operatorname{GABA}(\mathrm{A})$ receptor subunits on Renshaw cells: relationship with presynaptic neurotransmitters and postsynaptic gephyrin clusters. J. Comp. Neurol. 444, 275-289.

Giesemann, T., Schwarz, G., Nawrotzki, R., Berhörster, K., Rothkegel, M., Schlüter, K., Schrader,N., Schindelin, H., Mendel, R. R., Kirsch, J., and Jockusch, B. M. (2003). Complex formation between the postsynaptic scaffolding protein gephyrin, profilin, and Mena: a possible link to the microfilament system. J. Neurosci. 23, 8330-8339.

Gomeza, J., Hülsmann, S., Ohno, K., Eulenburg, V., Szöke, K., Richter, D., and Betz, H. (2003). Inactivation of the glycine transporter 1 gene discloses vital role of glial glycine uptake in glycinergic inhibition. Neuron 40, 785-796.

Graybiel, A. M. (1995). The basal ganglia. Trends Neurosci. 18, 60-62.

Grudzinska, J., Schemm, R., Haeger, S., Nicke, A., Schmalzing, G., Betz, H., and Laube, B. (2005). The beta subunit determines the ligand binding properties of synaptic glycine receptors. Neuron 45, 727-739.

Grunert, U., and Wassle, H. (1993). Immunocytochemical localization of glycine receptors in the mammalian retina. J. Comp. Neurol. 335, 523-537.

Harvey, R. J., Depner, U. B., Wassle, H., Ahmadi, S., Heindl, C., Reinold, H., Smart, T. G., Harvey, K., Schutz, B., Abo-Salem, O. M., Zimmer, A., Poisbeau, P., Welzl, H., Wolfer, D. P.,
Betz, H., Zeilhofer, H. U., and Muller, U. (2004). GlyR alpha3: an essential target for spinal PGE2-mediated inflammatory pain sensitization. Science 304, 884-887.

Harvey, R. J., Topf, M., Harvey, K., and Rees, M. I. (2008). The genetics of hyperekplexia: more than startle! Trends Genet. 24, 439-447.

Hoch, W., Betz, H., and Becker, C. M. (1989). Primary cultures of mouse spinal cord express the neonatal isoform of the inhibitory glycine receptor. Neuron 3, 339-348.

Keck, T., and White, J. A. (2009) Glycinergic inhibition in the hippocampus. Rev. Neurosci. 20, 13-22.

Kerwin, R. W., and Pycock, C. J. (1979) Specific stimulating effect of glycine on $3 \mathrm{H}$-dopamine efflux from substantia nigra slices of the rat. Eur. J. Pharmacol. 54, 93-98.

Kirsch, J., and Betz, H. (1993). Widespread expression of gephyrin, a putative glycine receptor-tubulin linker protein, in rat brain. Brain Res. 621, 301-310.

Kirsch, J., Meyer, G., and Betz, H. (1996). Synaptic targeting of ionotropic neurotransmitter receptors. Mol. Cell Neurosci. 8, 93-98.

Langosch, D., Becker, C. M., and Betz, H. (1990). The inhibitory glycine receptor: a ligand-gated chloride channel of the central nervous system. Eur. J. Biochem. 194, 1-8.

Levi, S., Chesnoy-Marchais, D. Sieghart, W., and Triller, A. (1999). Synaptic control of glycine and GABAA receptors and gephyrin expression in cultured motoneurons. J. Neurosci. 19, 7434-7449.

Liu, Q., and Wong-Riley, M. T. (2002). Postnatal expression of neurotransmitters, receptors, and cytochrome oxidase in the rat pre-Botzinger complex. J. Appl. Physiol. 92, 923-934.

Lloyd, K. G., DeMontis, G., Broekkamp, C. L., Thuret, F., and Worms, P. (1983). Neurochemical and neuropharmacological indications for the involvement of GABA and glycine receptors in neuropsychiatric disorders. Adv. Biochem. Psychopharmacol. 37, 137-148.

Lynch, J. W. (2004). Molecular structure and function of the glycine receptor chloride channel. Physiol. Rev. 84, 1051-1095.

McCool, B. A., and Botting, S. K. (2000). Characterization of strychninesensitive glycine receptors in acutely isolated adult rat basolatera amygdala neurons. Brain Res. 859, 341-351.

Meyer, G., Kirsch, J., Betz, H., and Langosch, D. (1995). Identification of a gephyrin binding motif on the glycine receptor beta subunit. Neuron $15,563-572$.
Naas, E., Zilles, K., Gnahn, H., Betz, H. Becker, C. M., and Schroder, H. (1991). Glycine receptor immunoreactivity in rat and human cerebral cortex. Brain Res. 561, 139-146.

Neuhoff, H., Sassoè-Pognetto, M., Panzanelli, P., Maas, C., Witke, W., and Kneussel, M. (2005). The actinbinding protein profilin I is localized at synaptic sites in an activity-regulated manner. Eur. J. Neurosci. 21, 15-25.

Nicoli, F., Vion-Dury, J., Maloteaux, J. M., Delwaide, C., Confort-Gouny, S. Sciaky, M., and Cozzone, P. J. (1993). CSF and serum metabolic profile of patients with Huntington's chorea: a study by high resolution proton NMR spectroscopy and HPLC. Neurosci. Lett. 154, 47-51.

Poulopoulos, A., Aramuni, G., Meyer, G., Soykan, T., Hoon, M., Papadopoulos, T., Zhang, M., Paarmann, I., Fuchs, C., Harvey, K., Jedlicka, P., Schwarzacher, S. W. Betz, H., Harvey, R. J., Brose, N., Zhang, W., and Varoqueaux, F. (2009). Neuroligin 2 drives postsynaptic assembly at perisomatic inhibitory synapses through gephyrin and collybistin. Neuron 63, 628-642.

Pfeiffer, F., Simler, R., Grenningloh, G., and Betz, H. (1984). Monoclonal antibodies and peptide mapping reveal structural similarities between the subunits of the glycine receptor of rat spinal cord. Proc. Natl. Acad. Sci. U.S.A. 81, 7224-7227.

Probst, A., Cortes, R., and Palacios, J. M. (1986). The distribution of glycine receptors in the human brain. A light microscopic autoradiographic study using $[3 \mathrm{H}]$ strychnine. Neuroscience 17, 11-35.

Racca, C., Gardiol, A., and Triller, A. (1997). Dendritic and postsynaptic localizations of glycine receptor alpha subunit mRNAs. J. Neurosci. 17, 1691-1700.

Rajendra, S., Lynch, J. W., and Schofield, P. R. (1997). The glycine receptor. Pharmacol. Ther. 73 121-146.

Rampon,C.,Luppi,P.H.,Fort,P.,Peyron, C., and Jouvet, M. (1996). Distribution of glycine-immunoreactive cell bodies and fibers in the rat brain. Neuroscience 75, 737-755.

Rees, M. I., Andrew, M., Jawad, S., and Owen, M. J. (1994). Evidence for recessive as well as dominant forms of startle disease (hyperekplexia) caused by mutations in the alpha 1 subunit of the inhibitory glycine receptor. Hum. Mol. Genet. 3, 2175-2179.

Rees, M. I., Harvey, K., Pearce, B. R., Chung, S. K., Duguid, I. C., Thomas, P., Beatty, S., Graham, G. E., Armstrong, L., Shiang, R.,Abbott, K. J., Zuberi, S. M., Stephenson, J. B., 
Owen, M. J., Tijssen, M. A., van den Maagdenberg, A. M., Smart, T. G., Supplisson, S., and Harvey, R.J. (2006). Mutations in the gene encoding GlyT2 (SLC6A5) define a presynaptic component of human startle disease. Nat. Genet. 38, 801-806.

Rees, M. I., Harvey, K., Ward, H., White, J. H., Evans, L., Duguid, I. C., Hsu, C. C., Coleman, S. L., Miller, J., Baer, K., Waldvogel, H. J., Gibbon, F., Smart, T. G., Owen, M. J., Harvey, R. J., and Snell, R. G. (2003). Isoform heterogeneity of the human gephyrin gene (GPHN), binding domains to the glycine receptor, and mutation analysis in hyperekplexia. J. Biol. Chem. 278 24688-24696.

Rees, M. I., Lewis, T. M., Kwok, J. B., Mortier, G. R., Govaert, P., Snell, R. G., Schofield, P.R., and Owen, M.J. (2002). Hyperekplexia associated with compound heterozygote mutations in the beta-subunit of the human inhibitory glycine receptor (GLRB). Hum. Mol. Genet. 11, 853-860.

Rees, M.I.,Lewis, T.M., Vafa, B., Ferrie, C., Corry, P., Muntoni, F., Jungbluth, H., Stephenson, J. B., Kerr, M., Snell, R. G., Schofield, P. R., and Owen, M. J. (2001). Compound heterozygosity and nonsense mutations in the alpha(1)-subunit of the inhibitory glycine receptor in hyperekplexia. Hum. Genet. 109, 267-270.

Reilmann, R., Rolf, L. H., and Lange, H. W. (1997). Huntington's disease: $\mathrm{N}$-methyl-D-aspartate receptor coagonist glycine is increased in platelets. Exp. Neurol. 144, 416-419.

Rubio, M. E., and Juiz, J. M. (2004). Differential distribution of synapticendings containing glutamate, glycine, and GABA in the rat dorsal cochlear nucleus. J. Comp. Neurol. 477, 253-272.

Sato, K., Zhang, J. H., Saika, T., Sato, M., Tada, K., and Tohyama, M. (1991). Localization of glycine receptor alpha 1 subunit mRNA-containing neurons in the rat brain: an analysis using in situ hybridization histochemistry. Neuroscience 43, 381-395.

Schroder, S., Hoch, W., Becker, C. M., Grenningloh, G., and Betz, H. (1991). Mapping of antigenic epitopes on the alpha 1 subunit of the inhibitory glycine receptor. Biochemistry 30, 42-47.

Schwaller, B., Buchwald, P., Blumcke, I., Celio, M. R., and Hunziker, W. (1993). Characterization of a polyclonal antiserum against the purified human recombinant calcium binding protein calretinin. Cell Calcium 14, 639-648.

Schwaller, B., Tetko, I. V., Tandon, P., Silveira, D. C., Vreugdenhil, M., Henzi, T., Potier, M. C., Celio, M. R. and Villa, A. E. (2004). Parvalbumin deficiency affects network properties resulting in increased susceptibility to epileptic seizures. Mol. Cell Neurosci. 25, 650-663.

Sergeeva, O. A. (1998). Comparison of glycine- and GABA-evoked currents in two types of neurons isolated from the rat striatum. Neurosci. Lett. 243, 9-12.

Sergeeva, O. A., and Haas, H. L. (2001). Expression and function of glycine receptors in striatal cholinergic interneurons from rat and mouse. Neuroscience 104, 1043-1055.

Shiang, R., Ryan, S. G., Zhu, Y. Z., Hahn, A. F., O'Connell, P., and Wasmuth, J. J. (1993). Mutations in the alpha 1 subunit of the inhibitory glycine receptor cause the dominant neurologic disorder, hyperekplexia. Nat. Genet. 5, 351-358.

Smith, Y., Bevan, M. D., Shink, E., and Bolam, J. P. (1998). Microcircuitry of the Direct and Indirect Pathways of the Basal Ganglia. Neuroscience 86, 353-387.

Smolinsky, B., Eichler, S. A., Buchmeier, S., Meier, J. C., and Schwarz, G. (2008). Splice-specific functions of gephyrin in molybdenum cofactor biosynthesis. J. Biol. Chem. 283, 17370-17379.

Todd, A. J., Spike, R. C., Chong, D., and Neilson, M. (1995). The relationship between glycine and gephyrin in synapses of the rat spinal cord. Eur. J. Neurosci. 7, 1-11.

Todd, A. J., Watt, C., Spike, R. C., and Sieghart, W. (1996). Colocalization of GABA, glycine, and their receptors at synapses in the rat spinal cord. J. Neurosci. 16, 974-982.

Triller, A., Cluzeaud, F., and Korn, H. (1987). gamma-Aminobutyric acid- containing terminals can be apposed to glycine receptors at central synapses. J. Cell Biol. 104, 947-956.

Triller, A., Cluzeaud, F., Pfeiffer, F., Betz, H., and Korn, H. (1985). Distribution of glycine receptors at central synapses: an immunoelectron microscopy study J. Cell Biol. 101, 683-688.

van den Pol, A. N., and Gorcs, T. (1988), Glycine and glycine receptor immunoreactivity in brain and spinal cord. J. Neurosci. 8, 472-492.

Wässle, H., Koulen, P., Brandstätter, J. H., Fletcher, E. L., and Becker, C. M. (1998). Glycine and GABA receptors in the mammalian retina. Vision Res. 38, 1411-1430.

Waldvogel, H.J., Baer, K., Allen, K. L., Rees, M.I., and Faull, R. L. M. (2007). Glycine receptors in the striatum, globus pallidus, and substantia nigra of the human brain: an immunohistochemical study. J. Comp. Neurol. 502, 1012-1029.

Waldvogel, H. J., Baer, K., Eady, E, Allen, K. L., Gilbert, R. T., Mohler, H., Rees, M. I., Nicholson, L. F. B., and Faull, R. L. M. (2009). Differential localisation of GABAA and glycine receptor subunits and gephyrin in the human pons, medulla oblongata and uppermost cervical segment of the spinal cord: an immunohistochemical study. J. Comp. Neurol. Accepted Article Online: Sep 16 2009. doi: 10.1002/cne.22212.

Waldvogel, H. J., Baer, K., Snell, R. G., During, M. J., Faull, R. L. M., and Rees, M. I. (2003). Distribution of gephyrin in the human brain: an immunohistochemical analysis. Neuroscience 116, 145-156.

Waldvogel, H. J., Billinton, A., White, J. H., Emson, P.C., and Faull, R. L. M. (2004) Comparative cellular distribution of GABAA and GABAB receptors in the human basal ganglia: immunohistochemical colocalization of the alpha 1 subunit of the GABAA receptor, and the GABABR1 and GABABR2 receptor subunits. J. Comp. Neurol. 470, 339-356.

Waldvogel, H. J., Curtis, M. A., Baer, K., Rees, M. I., and Faull, R. L. M. (2006), Immunohistochemical staining of post-mortem adult human brain sections. Nat. Protoc. 1, 2719-2732.
Waldvogel, H. J., Kubota, Y., Fritschy, J. M. Mohler, H., and Faull, R. L. M. (1999). Regional and cellular localisation of GABA(A) receptor subunits in the human basal ganglia: an autoradiographic and immunohistochemical study. J. Comp. Neurol. 415, 313-340.

Xu, X., Roby, K. D., and Callaway, E. M. (2006). Mouse cortical inhibitory neuron type that coexpresses somatostatin and calretinin. J. Comp. Neurol. 499, 144-160.

Yadid, G., Pacak, K., Golomb, E., HarveyWhite, J. D., Lieberman, D. M. Kopin, I. J., and Goldstein, D. S. (1993). Glycine stimulates striatal dopamine release in conscious rats. Br. J. Pharmacol. 110, 50-53.

Ye, J. H., Wang, F., Krnjevic, K., Wang, W. Xiong, Z. G., and Zhang, J. (2004). Presynaptic glycine receptors on GABAergic terminals facilitate discharge of dopaminergic neurons in ventral tegmental area. J. Neurosci. 24 8961-8974.

Zucker, C. L. (1998). Localization of gephyrin and glycine receptor subunit immunoreactivity in the rabbit retina. Vis. Neurosci. 15, 389-395.

Conflict of Interest Statement: The authors declare that the research was conducted in the absence of any commercial or financial relationships that could be construed as a potential conflict of interest

Received: 17 August 2009; paper pending published: 17 September 2009; accepted: 15 October 2009; published online: 04 November 2009.

Citation: Baer K, Waldvogel HJ, Faull RLM and Rees MI (2009) Localization of glycine receptors in the human forebrain, brainstem, and cervical spinal cord: an immunohistochemical review. Front. Mol. Neurosci. 2:25. doi: 10.3389/neuro.02.025.2009 Copyright (๑) 2009 Baer, Waldvogel, Faull and Rees. This is an open-access article subject to an exclusive license agreement between the authors and the Frontier Research Foundation, which permits unrestricted use, distribution, and reproduction in any medium, provided the original authors and source are credited. 